\title{
A new standard of care for forensic mental health treatment: prioritizing forensic intervention
}

\author{
Katherine D. Warburton*
}

California Department of State Hospitals, Sacramento, California, USA; Division of Psychiatry and the Law, University of California-Davis, Davis, California, USA

Many forensic psychiatric settings serve unique populations who have, in addition to traditional psychiatric symptoms, diverse legal and criminogenic needs. A lack of clear treatment standards that address all aspects of forensic care can lead to inefficient or inappropriate interventions and contribute to institutional violence.

Received 21 January 2015; Accepted 19 February 2015; First published online 17 April 2015

Key words: Forensic, forensic hospitals, standard of care, state hospitals, treatment.

\section{Introduction}

Forensic populations are increasing; however mental health treatment paradigms have not changed to accommodate this new population. The recovery principles that currently guide psychiatric delivery systems do not account for forensic environments, which are in themselves "settings in which self-determination is already strongly curtailed," nor do they answer the question of how a system designed to divert individuals from legal consequences based on their lack of competency or responsibility can at the same time be treated with a model that emphasizes full agency. ${ }^{1}$ This leads to a paradox for forensic hospital systems that are simultaneously trying to meet treatment standards grounded in recovery philosophy while at the same time addressing the unique needs of a forensic population (see Table 1).

\section{How Should State Hospitals Treat Forensic Patients? Is This an Unsolvable Problem?}

There is a new forensic population housed in state hospital systems. Many of these state hospitals are older facilities that employ clinical policies developed during the reforms of the 1960 s and 1970s. These "state" hospitals are often now referred to as "forensic hospitals,"

\footnotetext{
* Address for correspondence: Katherine Warburton, California Department of State Hospitals, 1600 9th Street, Suite 400, Sacramento, CA 95814, USA.

(Email: katherine.warburton@dsh.ca.gov)

The opinions expressed in this paper are the author's and do not reflect the views of any agency or entity with whom the author is affiliated.
}

most often due to the changed patient population rather than any updated infrastructure or practice. In general, state hospital systems have multiple oversight mechanisms. Despite these strict monitoring practices, state/ forensic hospitals can be plagued with problems, most notably inpatient violence, which frequently makes national headlines (sometimes international headlines), creating a treatment paradox in forensic psychiatry. ${ }^{2-20}$

For example, a single week of national headlines in 2014 illustrates the current problems confronted by facilities that are trying to deliver humane mental health services to populations with high levels of inpatient violence. On one day, the Hartford Courant reported on the controversial placement of a patient found not guilty by reason of insanity, because he was held on bail at a correctional institution rather than returned to the state/ forensic hospital where he had allegedly committed numerous serious assaults on patients and other staff. The patient was suing to return to the state/forensic hospital citing an entitlement to treatment. ${ }^{21}$ At issue was his level of violence risk and the inability of the hospital to provide the same level of safety as the correctional setting. The following day, the Associated Press reported that four Hawaii State Hospital employees were suing the state due to the unsafe work environment created by assaultive psychiatric inpatients in their state hospital. ${ }^{22}$ Later that same week, the Portland Press Herald reported on a controversy involving the allegedly punitive and controlling environment at the state/forensic hospital in Maine; in the same article, a psychiatrist on staff described the forensic unit as the most dangerous inpatient psychiatric unit that he had ever seen. ${ }^{23}$ Thus, three state/forensic 
hospitals attempted to handle the same situation (uncontrollable violence in inpatient forensic populations) three different ways, and all three approaches were flawed, controversial, and worthy of media attention. This week was not an anomaly; the issue of inpatient violence, especially among forensic patients and especially in state/ forensic hospitals, has been widely reported in the media over recent years. ${ }^{2-23}$ This is confounding, because most state/forensic hospitals receive a extensive amount of external oversight from state, private, advocacy, and federal agencies. Tremendous resources are expended trying to meet the mandated conditions of what these various agencies define as the standard of care for inpatient psychiatric facilities.

Frequently, this includes implementation of recovery principles, recovery-based multifocal treatment planning, active treatment in the form of multiple hours of group therapy each week, and the development of treatment malls. However, most forensic patients are sent to state/ forensic hospitals not to recover from their mental illness, but as a result of involvement in the criminal justice system. In many cases the recovery-based treatment planning and subsequent active treatment delivery do little to address the forensic or criminogenic needs of these patients, and failing to address these needs in lieu of comprehensive care based on recovery principles has the unintended effect of neglecting the most salient immediate clinical needs. Hence we have the continual cycle of violence, treatment disruption, and administrative changes in response to treatment and systemic failures that can be found in many state/forensic hospitals across the country.

Have state/forensic hospitals been handed an unsolvable problem, or is there a sweet spot between applied recovery principles and appropriate forensic treatment that will ensure that individuals with a combination of mental health and criminogenic needs will receive appropriate treatment in an appropriate environment? Is it time to develop new standards of care for forensic settings that prioritize the forensic and legal needs of these individuals?

\section{Who Are Forensic Psychiatric Patients?}

Broadly defined, forensic psychiatric patients are mental health patients who also have some involvement with the criminal justice system. Historically, the term "forensic patient" was used to describe a narrow class of individuals: those found "not guilty by reason of insanity" (NGRI) and those found "incompetent to stand trial" (IST). Adding to those traditional forensic commitments are inmates sentenced to correctional facilities (jails and prisons) who have mental illness; there is now a tremendous focus on the growing need for forensic psychiatric services in these settings. ${ }^{24,25}$ Newer commitment types, such as sexually violent predators (individuals who have completed a prison term but are retained for treatment due to a nexus between a psychiatric disorder and their sexual predation) and individuals who have completed a prison term but who are committed because they pose a high risk of violence due to their psychiatric disorder (referred to as "mentally disordered offenders" in California) add further diversity to this growing population. There is even some suggestion that the term "forensic patient" should be expanded to include patients involuntarily committed by a civil court. ${ }^{26}$ Anecdotal reports indicate an increasing level of criminal behavior and violence even in these "civil" commitments, perhaps due to the successful social movement that ensures that people who can be safely treated in the community are treated in the

TABLE 1. The forensic paradox

Recovery is person-driven.

Self-determination and self-direction are the foundations for recovery as individuals define their own life goals and design their unique path(s) toward those goals. Individuals optimize their autonomy and independence to the greatest extent possible by leading, controlling, and exercising choice over the services and supports that assist their recovery and resilience. In so doing, they are empowered and provided the resources to make informed decisions, initiate recovery, build on their strengths, and gain or regain control over their lives.

Recovery is holistic.

Recovery encompasses an individual's whole life, including mind, body, spirit, and community. This includes addressing self-care practices, family, housing, employment, transportation, education, clinical treatment for mental disorders and substance use disorders, services and supports, primary healthcare, dental care, complementary and alternative services, faith, spirituality, creativity, social networks, and community participation. The array of services and supports available should be integrated and coordinated.
The defendant is unable to understand the charges and/or does not have the ability to aid attorney in own defense.

It must be clearly proved that, at the time of the committing of the act, the party accused was laboring under such a defect of reason, from disease of the mind, as not to know the nature and quality of the act he was doing; or, if he did know it, that he did not know he was doing what was wrong.

"Sexually violent predator" means a person who has been convicted of a sexually violent offense against one or more victims and who has a diagnosed mental disorder that makes the person a danger to the health and safety of others, in that it is likely that he or she will engage in sexually violent criminal behavior.

As a result of the severe mental disorder, the prisoner represents a "substantial danger of physical harm to others." 
community, thereby increasing the concentration of violence in involuntary civil state hospital settings. Regardless, the fact that forensic treatment needs are growing, both in state psychiatric institutions as well as correctional environments, is clear. ${ }^{27-30}$ The most well-supported explanation for this growth is the phenomenon of the "criminalization" of mentally ill populations. In short, this social trend began when mental health patients who would have been served in state institutions were instead deinstitutionalized. For a variety of reasons, most notably withdrawal of federal funding, these patients were not provided with adequate care or treatment in the community, and thus began drifting into illegal activities and arrest. Therefore, many forensic patients end up in correctional environments, while others are captured by mental health law and adjudicated to state mental hospitals. ${ }^{31-35}$ There is evidence that this growing population has features of both mental illness and criminal thinking. ${ }^{36-41}$ There is also evidence that forensic hospitals are no longer treating categorical diagnoses, but are instead treating violence, and this poses a challenge to these facilities. ${ }^{42,43}$

\section{The Current Standard of Care for State Hospitals Does Not Work for Forensic Populations}

The definition of the term "standard of care" has much more of a legal basis than a medical one, but in general it can be summarized as how similarly qualified practitioners would have managed care under the same or similar circumstances. ${ }^{44}$ Existing treatment standards for psychiatric inpatients represent an entirely appropriate evolution of practice following the institutional abuses of the 1950s and 1960s. But they are not appropriate for violent forensic populations, precisely because circumstances have changed, including patient profiles and precipitants for hospitalization.

One historical English law test for the standard of care, the Bolam test, was ultimately rejected because it "allows the standard in law to be set subjectively by expert witnesses" in favor of the Bolitho decision that "standards proclaimed must be justified on a logical basis and must have considered the risks and benefits of competing options." 45 Given the increasing struggles to safely and humanely treat the growing forensic population, examining the current standard of care from a perspective of logic and risk/benefit analysis is warranted. While there are multiple guidelines for treating psychiatric patients in public, private, and even in correctional settings, very little exists on treating forensic patients in state hospital settings, rendering mandates somewhat subjective. ${ }^{46-48}$ For the forensic patients found not guilty by reason of insanity or incompetent to stand trial, guidelines tend to focus on initial evaluation rather than subsequent treatment of dangerousness, barriers to trial competency, and/or criminogenic needs.

Complicating the treatment of mental illness in the modern state/forensic psychiatric facility is the recognition that many forensic patients evidence both bona fide mental health symptoms and criminogenic thinking, contributing to what may be a new type of patient with new treatment needs. ${ }^{36-41}$ As such, a standard of treatment designed to facilitate recovery in a civilly committed patient without concomitant criminal behaviors and/or criminal justice system involvement may not be effective for this new population. An examination of forensic commitment criteria indicates that most forensic commitment language can be translated into two primary discharge criteria: restoration of competence and/or the ability to be safely treated in the community. It is therefore logical that forensic treatment would be focused on restoration to competence and/or mitigation of violence risk, with an eye toward addressing learned criminogenic attitudes. However, as a carryover from the standards set for the older state hospital system, treatment is often not focused this way, but rather on reduction of symptoms of psychiatric disorders within a holistic framework of recovery concepts such as selfdirection and autonomy. This is not to suggest that treating psychiatric disorders with a recovery framework is not important, but rather that for forensic patients, addressing their forensic commitment criteria and reducing criminal behavior, including violence, is more so. As such, the recovery approach in the state/forensic psychiatric hospital would be better seen as part of a continuum of care where the patient can be discharged to the community after violence mitigation is successful, for recovery in that setting. ${ }^{49}$

For example, approximately $15-20 \%$ of patients referred as incompetent to stand trial may actually be malingering to avoid adjudication. ${ }^{50,51}$ For those individuals, screening for malingering and follow-up forensic evaluation should be the focus of treatment, rather than recovery from a mental illness that is feigned to begin with. For patients who evidence predatory aggression rooted in psychopathic characteristics, principles of self-direction are inappropriate and put other patients at risk. For patients who have been diverted from court or prison because they are not competent or not criminally responsible, the concept of autonomy can be difficult to reconcile.

It appears that the standard of care needs to be defined for these commitment types as well as other patients now confined to state/forensic facilities, including those serving criminal sentences and referred from prisons, those referred from prisons as a condition of parole, sex offenders, and even seriously ill and violent civilly committed individuals who are unable to be safely treated in the community. ${ }^{52}$ 


\section{Why a New Standard Will Matter}

In current forensic treatment environments, uncontrolled inpatient violence interferes with patient and staff safety, as well as treatment delivery. Available interventions to control violence include seclusion and restraint, 1:1 observation, and PRN medications. Both seclusion and restraint, and PRN medication are heavily weighted toward psychotic violence, which is easier to predict and medicate, but far less common, than other types of inpatient aggression. ${ }^{53,54}$ Prediction and prevention of inpatient aggression in a forensic setting is more appropriately done via violence risk assessment techniques and proper level of custodial security based on overall risk level, rather than "imminent" risk level based on antecedent behaviors that might not exist in the predatory or impulsive patient. Utilizing the presence of 1:1 observation is the practice devoting one staff member to observe an individual who has been identified as potentially violent to others. In many cases, this practice provides that patient with a target, puts our level of care staff at unacceptable risk, and drives up overtime and worker's compensation costs. Additionally, outcomes measures such as symptom reduction and length of stay do not necessarily measure whether the forensic goals (competency, violence mitigation) have been met. Focusing care primarily on outdated emergency interventions and recovery-based treatment planning, rather than reduction of risk and restoration of competency, can result in the unintended consequence of delaying discharge and violating the major dimensions needed to support recovery principles, such as the need for a stable and safe place to live. ${ }^{55}$

\section{Conclusion}

Evidence suggests that there is a new type of patient, and that we therefore need a new standard of treatment. Modern forensic treatment should not be primarily focused on recovery from a mental illness, but instead on reducing violence and meeting forensic discharge criteria in order to eventually return patients to recovery environments in the community.

\section{Disclosures}

The author does not have anything to disclose.

\section{REFERENCES:}

1. Pouncey CL, Lukens JM. Madness versus badness: the ethical tension between the recovery movement and forensic psychiatry. Theor Med Bioeth. 2010; 31(1): 93-105.

2. Laurence E. Report into psychiatric ward killing exposes uncoordinated health system. AM with Chris Uhlmann. November 3 , 2014. http://www.abc.net.au/am/content/2014/s4119995.htm.
3. Kalamazoo authorities seeking assault charges against psychiatric hospital workers. WKZO Kalamazoo. December 24, 2014.

4. Napa State Hospital psychiatric worker slain. San Francisco Chronicle. October 25, 2010. http://www.sfgate.com/health/ article/Napa-State-Hospital-psychiatric-worker-slain-3248688.php

5. Treatment problems, fear found in state's high-security mental hospital, workers say. Baltimore Sun. November 7, 2011. http://articles. baltimoresun.com/2011-11-07/health/bs-hs-perkins-fear-

20111107_1_patients-maximum-securitypsychiatric-hospital-susan-sachs

6. Perkins patients can be the toughest to treat. Baltimore Sun. November 20, 2011. http://articles.baltimoresun.com/2011-11-20/ health/bs-hs-perkins-treatment-20111120_1_perkins-patientsdangerous-patients-fewer-hospital-beds

7. Violence and fear in state mental hospitals on the rise nationally. Baltimore Sun. November 24, 2011. http://articles.baltimoresun. com/2011-11-24/news/bs-ed-perkins-20111124_1_donna-grossperkins-patients-mentally-ill-patients

8. Our view: forensic patients swamp state mental hospital. The Portland Press Herald. August 25, 3013. http://www.pressherald. com/opinion/forensic-patients-swamp-state-mental-hospital_201308-25.html?pagenum5full

9. DHHS commissioner blames growth in court ordered patients for Riverview problems; urges passage of LePage's plan. WABI TV5. August 22, 2013.

10. ABC 15 investigation exposes a "shocking" level of violence at the Arizona State Hospital. $A B C$ 15. August 9, 2013.

11. Violence at Texas mental hospitals on rise. United Press International. January 27, 2013. http://www.upi.com/Top_News/ US/2013/01/27/Violence-at-Texas-mental-hospitals-on-rise/UPI96021359313991/

12. Violence on the rise at Western State Hospital. Northwest Public Radio. May 3, 2012.

13. Patient violence jumps at state psychiatric hospitals. Statesman. January 26, 2013. http://www.statesman.com/news/news/local/ patient-violence-jumps-at-state-psychiatric-hospit/nT7GH/

14. Assaults on staff are focus of scathing report at Catonsville Psychiatric Hospital. Baltimore Sun. March 2, 2013. http://www. baltimoresun.com/news/maryland/baltimore-county/catonsville/ bs-md-co-spring-grove-report-20130302,0,7658971.story

15. Hegedus N. Danger at Mid-Hudson Psych: "I'm just waiting for a staff member to come out dead." Times-Herald Record. Undated. http://www.nyscopba.org/mid-hudson-psych-center-danger

16. State mental hospitals remain violent, despite gains in safety. Los Angeles Times. October 9, 2013. http://articles.latimes. com/2013/oct/09/local/la-me-mental-hospital-safety-20131010

17. Zimmerman M. Safety inspectors investigating violence at Hawaii State Hospital. Hawaï Reporter. December 5, 2013. http://www. Hawaiireporter.com/federal-safety-inspectors-investigating-violenceat-hawaii

18. Violence at California Mental Hospitals: "This is the norm." NPR. July 21, 2011.

19. Ontario mental health facility faces charges over worker safety violations. The Canadian Press. December 24, 2014. http://toronto. ctvnews.ca/ontario-mental-health-facility-faces-charges-overworker-safety-violations-1.2161643

20. Canzano A. Daily attacks common at the Oregon State Hospital, some say. KATU.com. April 18, 2013. http://www.katu.com/news/ investigators/Daily-attacks-common-at-the-Oregon-State-Hospitalemployees-say-203717621.html

21. Griffen A. Too dangerous for psych hospital? Man acquitted for insanity now in prison after violent assaults. Hartford Courant. September 23, 2014. http://www.courant.com/news/connecticut/ hc-anderson-cvh-court-hearing-advance-0924-2

22. Associated Press. Hawaii State Hospital employees sue over assaults. Washington Post. September 24, 2014. http://www.washingtontimes. 
com/news/2014/sep/24/hawaii-state-hospital-employees-sue-overassaults/.

23. Lawlor J. At state-run Riverview, danger and dysfunction pervasive. Portland Press Herald. September 21, 2014. http://www. pressherald.com/2014/09/21/at-state-run-riverview-danger-anddysfunction-pervasive/

24. Metzner JL, Dvoskin JA. Psychiatry in correctional settings. In: Simon RI, Gold LH, eds. Textbook of Forensic Psychiatry. American Psychiatric Publishing Inc. Washington DC; 2004: 377-391.

25. Psychiatric Services in Jails and Prisons: A Task Force Report of the American Psychiatric Association. Published by the American Psychiatric Association, Washington DC; 2000.

26. Bloom JD, Krishnan B, Lockey C. The majority of inpatient psychiatric beds should not be appropriated by the forensic system. J Am Acad Psychiatry Law. 2008; 36(4): 438-442.

27. Lamb HR, Weinberger LE. Persons with severe mental illness in jails and prisons: a review. Psychiatr Serv. 1998; 49(4): 483-492.

28. Fazel S, Seewald K. Severe mental illness in 33,588 prisoners worldwide: systematic review and meta-regression analysis. $\mathrm{Br} \mathrm{J}$ Psychiatry. 2012; 200(5): 364-373.

29. Torrey EF, Kennard AD, Eslinger D, et al. More mentally ill persons are in jails and prisons than hospitals: a survey of the states. Treatment Advocacy Center and National Sheriff's Association 2010. http://www.treatmentadvocacycenter.org/storage/ documents/final_jails_v_hospitals_study.pdf.

30. Lutterman T. National Association of State Mental Health Program Directors Research Institute Fiscal Year 2010 Revenues and Expenditure Study Results; 2012. http://media.wix.com/ugd/ 186708_c6beb833346b45429322cc4421d83aa1.pdf

31. Torrey EF. American psychosis: how the federal government destroyed the mental illness treatment system. Oxford University Press, Oxford, UK; 2013.

32. Mundt AP, Chow WS, Arduino M, et al. Psychiatric hospital beds and prison populations in South America since 1990: does the Penrose hypothesis apply? JAMA Psychiatry. 2015; 72(2): 112-118.

33. Abramson MF. The criminalization of mentally disordered behavior: possible side effect of a new mental health law. Hosp Community Psychiatry. 1972; 23(4): 101-105.

34. Swank GE, Winer D. Occurrence of psychiatric disorder in a county jail population. Am J Psychiatry. 1976; 133(11): 1331-1333.

35. Sosowsky L. Crime and violence among mental patients reconsidered in view of the new legal relationship between the state and the mentally ill. Am J Psychiatry. 1978; 135(1): 33-42.

36. Morgan RD, Fisher WH, Duan N, Mandracchia JT, Murray D. Prevalence of criminal thinking among state prison inmates with serious mental illness. Law Hum Behav. 2010; 34(4): 324-336.

37. Moran P, Hodgins S. The correlates of comorbid antisocial personality disorder in schizophrenia. Schizophr Bull. 2004; 30(4): 791-802.

38. Maghsoodloo S, Ghodousi A, Karimzadeh T. The relationship of antisocial personality disorder and history of conduct disorder with crime incidence in schizophrenia. J Res Med Sci. 2012; 17(6): 566-571.

39. Gross NR, Morgan RD. Understanding persons with mental illness who are and are not criminal justice involved: a comparison of criminal thinking and psychiatric symptoms. Law Hum Behav. 2013; 37(3): 175-186.
40. Wilson AB, Farkas K, Ishler KJ, Gearhart M, Morgan R, Ashe M. Criminal thinking styles among people with serious mental illness in jail. Law Hum Behav. 2014; 38(6): 592-601.

41. Wolff N, Morgan RD, Shi J, Huening J, Fisher WH. Thinking styles and emotional states of male and female prison inmates by mental disorder status. Psychiatr Serv. 2011; 62(12): 1485-1493.

42. Warburton $\mathrm{K}$. The new mission of forensic mental health systems: managing violence as a medical syndrome in an environment that balances treatment and safety. CNS Spectr. 2014; 19(5): 368-373.

43. Stahl SM. Deconstructing violence as a medical syndrome: mapping psychotic, impulsive, and predatory subtypes to malfunctioning brain circuits. CNS Spectr. 2014; 19(5): 355-365.

44. Moffett P, Moore G. The standard of care: legal history and definitions: the bad and good news. West J Emerg Med. 2011; 12(1): 109-112.

45. Strauss DC, Thomas JM. What does the medical profession mean by the "standard of care?" J Clin Oncol. 2009; 27(32): e192-e193.

46. Menzies RJ, Webster CD. Fixing forensic patients: psychiatry recommendations for treatment settings in pretrial detainees. Behav Sci Law. 1988; 6(4): 453-478.

47. Zapf PA, Roesch R. Future directions in the restoration of competency to stand trial. Current Directions in Psychological Science. 2011; 20(1): 43-47.

48. Scott CL. Commentary: a road map for research in restoration of competency to stand trial. J Am Acad Psychiatry Law. 2003; 31(1) 36-43.

49. Parks J, Radke AQ, Haupt MB. The vital role of state psychiatric hospitals. National Association of State Mental Health Program Directors Medical Directors Council Technical Report. 2014. www. nasmhpd.org.

50. Vitacco MJ, Rogers R, Gabel J, Munizza J. An evaluation of malingering screens with competency to stand trial patients: a known-groups comparison. Law Hum Behav. 2007; 31(3): 249-260.

51. Rogers R, Salekin RT, Sewell KW, Goldstein A, Leonard K. A comparison of forensic and nonforensic malingerers: a prototypical analysis of explanatory models. Law Hum Behav. 1998; 22(4): 353-367.

52. Linhorst DM, Scott LP. Assaultive behavior in state psychiatric hospitals: differences between forensic and nonforensic patients. J Interpers Violence. 2004; 19(8): 857-874.

53. Nolan KA, Czobor P, Roy BB, et al. Characteristics of assaultive behavior among psychiatric inpatients. Psychiatr Serv. 2003; 54(7): 1012-1016.

54. Quanbeck CD, McDermott BE, Lam J, et al. Categorization of aggressive acts committed by chronically assaultive state hospital patients. Psychiatr Serv. 2007; 58(4): 521-528.

55. Substance Abuse and Mental Health Services Administration. SAMHSA's Working Definition of Recovery. http://store.samhsa. gov/shin/content//PEP12-RECDEF/PEP12-RECDEF.pdf.

56. Dusky v. United States, 362 U.S. 402 (1960).

57. Re Daniel M'Naghten, 8 ER 718 (House of Lords, 1943).

58. California Welfare and Institution Code 6600 (a) 1.

59. California Penal Code 2972 (e). 